\title{
The complex system of knowledge economy and the quest of governance for stakeholders' networks
}

Modern firms are adapting to the dynamic and knowledge intensive conditions of globalised markets employing different organizational elements. The role of stakeholders and networks are shaping the boundaries of enterprises, and managerial literature is analyzing these changes trough the tools provided by transaction costs economics and resource-based theory (Morroni, 2011; Aoki, 2010; Pitelis and Teece, 2009; Williamson, 1995). These approaches are considered particularly suitable for a context of complex knowledge interactions in conditions of uncertainty, because they allow for bargaining and contractual hazards. However, the radical changes of the last decades have not involved only the models of organization of the enterprises, but the entire production structure and the relation between firms and economic environment (Verbeke and Tung, 2012; Rullani, 2009; Rajan and Zingales, 2000; Nahapiet and Goshal, 1997). Managerial literature is then developing an original analysis of the architecture of modern enterprises, looking at new key variables for a successful competition in the market (Crilly and Sloan, 2012; Harrison et al., 2010).

In this research we try to use concepts and tools from complexity theory, systems dynamics and evolutionary economics for drawing a model of the knowledge network that constitutes the "social capital" of the firm, looking not at the quantity of connections (network's dimension) but at their quality (network's value) and dynamic development.

In particular, we will investigate how (and when) firms collect and utilize information about a stakeholder's utility function to create new sources of value, that takes to analyse also which kind of knowledge can be useful for each firm and what are the costs.

Our analysis is aimed to evaluate the complex dynamics of firms' interactions in an uncertain environment. We will attempt to outline, also by means of a formal approach, a model to assess the evolution of firms' social capital toward value creation. In this paper we draw a "schema" to help understanding some complex strategic settings, analyzing if and how some network ties can create value or chaos, producing or dissipating resources.

\section{Fundamental changes in the model of the firm}

During the last twenty years, the traditional business corporation, emerged in the early $20^{\text {th }}$ century, has faced dramatic changes, concerning the internal organisation, the crucial assets and the productive structure ${ }^{1}$.

\footnotetext{
*Full Professor of Management, Economics and Marketing Department, IULM University, Milan.

** Assistant Professor of Management, Department of Economics and Statistics “S. Cognetti de'Martiis”, Università di Torino.
}

${ }^{1}$ See, among others, Harris and Raviv, 1991; Hobday, 1998; Zingales, 2000; Antonelli, 2008. 
For Chandler (1990), the primary advantage of the traditional model of corporation was its scale and scope: in the business reality the economies of scale of traditional industries, together with the mass advertising of their brands, have constituted strong barriers to the competition of new entrants, resulting in a limited competition in the final output markets (Rajan and Zingales, 2000). In this context, the interests of the company are different with those of society. For society, the more competition, the better. But for individual companies, the objective of the strategy is to reduce the play of competition, to get as much as possible for themselves.

Several industries, then, came to be dominated by a small number of vertically integrated giants, with few independent suppliers in intermediate markets. The very low competition in the intermediate markets led to several organizational consequences. Through its control of the firm's assets, headquarters effectively controlled the main source of employment, giving to the top management an enormous power and an accumulation of organizational surplus in their hands (Milgrom and Roberts, 1992). The different parts of the enterprise were managed trough an organizational hierarchy that was the sole programming engine of the company, in this way removing from middle managers the responsibility to define the meaning of what is being doing and to regenerate the reliability of relations with the rest of the world (Rullani, 2009). The search for satisfactory solutions should identify any replicable routine able to simplify the management and decision-making required by organizations: it addressed only the things that did not "work" (have performance below the minimum threshold permitted) and for the rest replicated what instead "works". This was a knowledge "reproducible" trough protocols, thought to be replicable at no cost, rapidly and with high guarantees of success in many different contexts. This paradigm could be functional to large scale and mature industries, because it is totally impersonal and acontextual, as it makes irrelevant the individual participation and knowledge contribution. Many industries were then giving the power over important decisions to impersonal automatism, following internal logic of functional optimization and eventually creating a fast capitalism of replication, which initially appeared successful, but that has been in fact unable to reproduce its premises in the long run. The result has been a clear paradigm of value production that Rullani (2009), with an vivid expression, calls mechanistic/authoritarian.

This last globalisation process we are living in has increased the demand for process innovation and quality improvement, raising a new global competition at the intermediate goods level with a consequent breakdown of the vertically integrated firm and the emerging of human capital as a crucial asset (Rajan and Zingales, 2001). This has made evident that "the firm is not anymore a well-bounded organisation" that we can "take for granted" (Zingales, 2000). Economic approaches based on market imperfections, namely the asymmetry of information and the problems coming from the principal-agent bargaining, derive directly from traditional models of firm. Some economists several years ago were already claiming that other patterns seems to be underexplored, "while the asymmetric information approach has reached the points of diminishing returns" (Harris and Raviv, 1991) about the capability of analyzing investment dynamics and value creation.

However, economists still attempt to design models feasible for a relatively stable long-term growth towards an equilibrium: the so-called "endogenous growth" theories, emerged in the last decades, try to combine the neoclassical equilibrium analysis with the Schumpeterian tradition about innovation trough the crucial role of skilled labor. In fact, these theories give just some partial insights on firms' growth processes, assuming that innovations are introduced smoothly in a market characterized by a monopolistic competition with a variety of products, drawing from 
the same pool of generic knowledge, which is considered as an Arrovian public good (Romer, 1990 and 1986; Aghion and Howitt, 1998) ${ }^{2}$. These models derive in fact from the neoclassical view of the firm as a legal entity with a production set (a set of viable production plans) the knowledge of which is presumably common. From such a set a manager acts rationally with full information, choosing the one most likely to maximize profits or the present value of the firm. The "contractual view" of the firm, developed by Coase (1937), Jensen and Meckling (1976) and Williamson (1985), relies on the notion of separation between ownership and control. This means that an entrepreneur, or a manager, raises funds from investors to put them to productive use, while financiers need the manager's specialized human capital to generate returns on their funds. But financiers cannot be sure that their funds will not be expropriated or wasted on bad projects $^{3}$. The concentration of power at the top of the organizational pyramid, together with the separation between ownership and control, made the agency problem between top managers and shareholders the corporate governance problem (Shleifer and Vishny, 1997). Then, most of traditional financial literature has been devoted to analyze if (and how) credit and equity markets can be considered able to monitoring efficiently the firms (Jensen, 1986; Stulz, 1990; Diamond, 1991; Harris and Raviv, 1990; Hart and Moore, 1995; Holmstrom and Tirole, 1993; Grossman and Hart, 1980 and Shleifer and Vishny, 1986).

In fact, this analysis gives just some partial insights on firms' growth processes. For the endogenous growth theories economic growth relies upon the collective access to generic knowledge, which flows in the air and retains the typical features of the Arrovian public good ${ }^{4}$. The introduction of innovations takes place smoothly in a market characterized by a monopolistic competition with a variety of products, drawing from the same pool of generic knowledge (Romer, 1990 and 1994; Aghion and Howitt, 1998). The complementarities between research and learning by doing stressed by the endogenous growth theories can be accommodated in this framework, so looking at the way an increase in the productivity of learning by doing will generate higher rents, and how they are shared. The theoretical justification for this context was derived from a view of the firm where each party belonging to the "nexus of contracts" has contractual claims on the surplus with pre-determined payoffs (Fama and Jensen, 1983). The exceptions are the shareholders, who accept a residual payoff because they have a comparative advantage in diversifying risk. In this context, the scholars of the new growth theory stressed the advantages of each system (debt or equity) arising from the relative effectiveness in spreading information about firm prospects and research activity in order to create technological spillovers and facilitate monitoring. But this financial side of the

\footnotetext{
${ }^{2}$ Some economists (i.e. Zingales, Rajan and Zingales) propose this view of the firm based on human capital as foundation also for a model of finance, but using such contractual view of the firm centered on the highly skilled employees doesn't provide convincing solutions for the dynamics of an enterprise facing a discontinuity (i.e. an innovating phase), always clashing at the end against the rationing of credit by financiers, caused by the uncertain perspective.

${ }^{3}$ A vast managerialist literature explains how managers use their effective control rights to pursue projects that benefit them rather than investors (Baumol, 1959; Williamson, 1964; Jensen, 1986; Grossman and Hart, 1988). Managerial opportunism, whether in the form of expropriation of investors or of misallocation of company funds, reduces the amount of resources that investors are willing to put up ex ante to finance the firm (Williamson, 1985; Grossman and Hart, 1986).

${ }^{4}$ The spillover of generic knowledge helps the generation of specific technological knowledge, which is embodied in new products and processes and it is highly idiosyncratic, so that can be appropriated without reducing the incentives to the generation of new knowledge.
} 
models come directly from a traditional view of the firm ${ }^{5}$ : the efforts to design a new endogenous innovation process without undermining the traditional view of the firm, do not add new hints to the comprehension of the management of the various knowledge assets of the firm and their possible contribution to a growth path. In this view, maximization of shareholders' value should necessarily lead to maximization of the value of the enterprise.

Nevertheless, in a world of incomplete contracts and multiple sources of power, the contractual protection provided to the parties in the nexus of contracts is necessarily incomplete. There are many residual claimants, so to privilege the shareholders (or even worst, just the controlling shareholders) can take to serious distortions in the risk management of a company with possible consequences on the firms' financial equilibriums. Eventually, maximization of shareholders' value does not necessarily lead to maximization of enterprise value.

In the next paragraphs, we will show that the role of knowledge and the interactions with the various subjects around the firm must be the core of the analysis for "understanding the connection between assets in place and growth opportunities" (Zingales, 2000), trough a more realistic and updated description of the mechanisms of the "black box".

\section{New insights for new systems dynamics}

Evolutionary literature about innovation and resources ${ }^{6}$ permits to break the notion of localised technological knowledge away from the sole contribution of human capital. Knowledge is linked to a larger definition of "production space" that considers the local characteristics in terms of productive history, factors endowment, relations between economic agents etc., such that it is not an exclusive patrimony of few specialized workers. Merging the resource-based approach with stakeholder management (Verbeke and Tung, 2012) emphasizes the importance of the social construction of a network of stakeholders as resource providers, who help the firm to compete successfully in the market. This is not just the technical processes of accumulating and combining resources with value-creating features, but it is the recognition that a firm's stakeholder network can be in itself a source of competitive advantage (Harrison et al., 2010; Rullani, 2009).

\footnotetext{
5 Jensen and Meckling (1976), Ross (1977) and Harris and Raviv (1991) already argued that leverage-increasing issues are generally viewed as positive signals because debtholders seem to monitor investors more closely than shareholders and also because limited free cash flow reduces the possibility that managers pursue non profit rentseeking activities.

${ }^{6}$ On the side of the theory of the firm, theories has been developed about the co-evolution of technology, industry and market structure within an "evolutionary" context (Nelson and Winter, 1973,1974; Rosenberg, 1976), with "innovation systems" characterized at the level of a nation (Freeman, 1988; Lundvall, 1992; Nelson, 1993), an industry (Mowery and Nelson, 1999) or a technology (Carlsson, 1995) looking at the changes occurred in markets and at the effects of these changes on the production structure of modern companies, enhancing the fundamental contributions of Penrose (1959) and Chandler (1977) about learning and knowledge resources.
} 


\section{Figure 1: Foundations of the model}

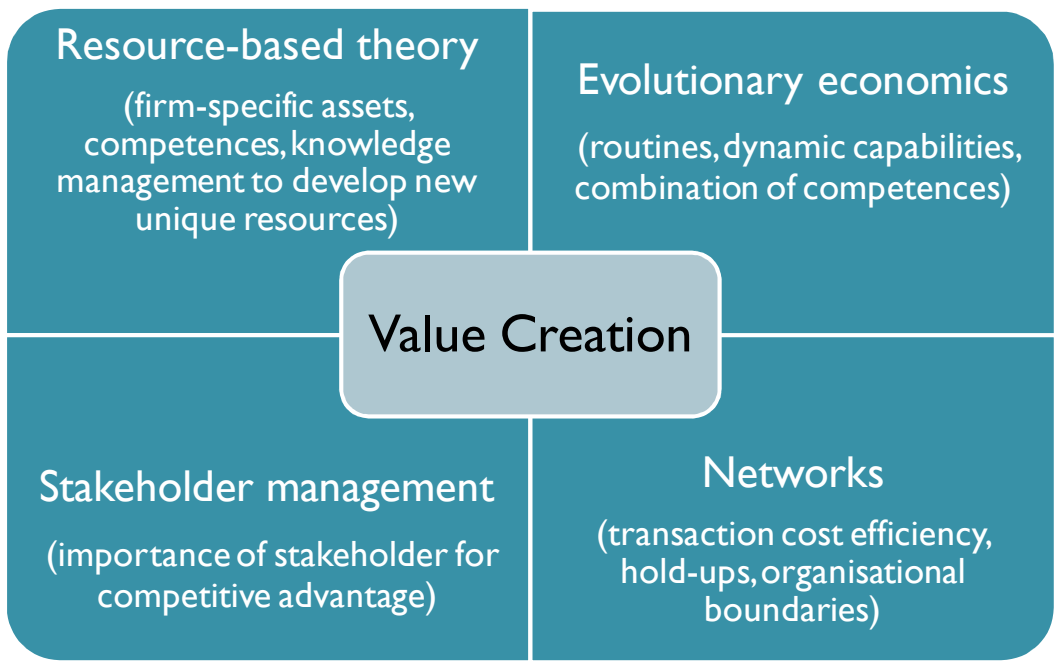

Two new crucial features come out from this theoretical evolution: knowledge and network. These factors are central for understanding and evaluating the firm's capabilities to innovate (Maturana and Varela, 1992). The firm is not anymore an impersonal nexus of contracts, but rather a selective and selected combination of complementary activities based upon the capability to accumulate competence and knowledge.

A "systemic" view of the firm, assuming the variety of firms in terms of product and factor markets, explains how to create value trough the interaction and competition in the market place of agents, which are able, by means of systemic learning processes (learning by doing; learning by using; learning by consuming etc.), to accumulate technological knowledge and to generate and to adopt new technologies, in a continuous exchange with the economics systems where they are operating (Vicari and Cillo, 2006). This theoretical evolution has opened a new vision about the utilization by the firm of its resources, and about the relationship with the maximisation of the value: this change needs a new methodology to analyse these complex features.

Literature on complexity shows that a system changes its behavior in relation to the diverse results obtained, because is not attached to a invariant model of conduct, but to a certain performance to be achieved, such that it gets different adaptations in different contexts. This relationship with the performance is not purely mechanical, but it is based on feedback, namely the capacity to correct the effects of actions when they do not guarantee the performance due. Feedback corrects, but if the system is quite flexible, it can also be a source of evolutionary learning: the system changes its behavior, its routines, its organizational structures, trying new combinations in all these fields. In addition, we sustain that this evolutionary learning is not based on "automatic" feedback, but it is the result of the ability and willingness of the various parties to continually regenerate the foundations of their relationship and their sharing: firm's competitive advantage is the outcome of deliberate resources selection, access, accumulation, and recombination, based on systematic assessment and value-optimizing, managerial decisions in a context of resource mobility barriers (Crilly and Sloan, 2012; Ginsberg 1994; Zajac and Bazerman 1991). 
This strategy can take place because firms understood what benefits are linked to bind and to share. The decision to start the sharing process is accompanied by concepts of distributional, procedural, and interactional justice (Harrison et al., 2010), which regulate network ties based on identity, codes, measures and contracts that make the business relation reliable, so promoting mutual specialization. Goshal and Nahapiet (1998) have described this relationship between this "social" capital external to the enterprise and the internal human capital of the firm. The latter has skills and knowledge for developing appropriate and innovative practices designed to improve performance and survivability of firms in dynamic contexts. This can happen trough the combination of skills not previously linked, or through new ways to combine elements already connected, with an exchange of expertise which is either intrasystemic and intersystemic ${ }^{7}$.

In this research, we define social capital as the main way to develop the knowledge of the firm in consonance with the surrounding context. A consonance that represents "the implementation / maintenance of conditions of harmony, correspondence, alignment and dialogue between corporate values and the cultures and needs of the surrounding society" (Golinelli, 2008) ${ }^{8}$. Eventually, the business models pluralize because in the network process of value creation there must be many and varied contributions (Morroni, 2011). When stakeholders are able to help with their behavior to reduce costs and increase the total utility produced, then competitiveness becomes an attribute that cannot be applied to individual firm, but must be reported to the chain or network affiliation. In this context we can assume knowledge as intrinsically indivisible but, at the same time, dispersed in a variety of individuals, no one of which can claim to control it entirely (Antonelli, 2003). Knowledge is then re-composed and directed to the creation of value when there is a "strategic focus" between the interacting subjects, whose objectives are closely tied and based on the same critical variables (Peirone, 2007). This is why the complementarity among the various agents in the network is central in the accumulation, generation and eventual valorization of knowledge. The firm can be considered the institution that is better able to manage such complementarities in a market economy (Miglietta and Peirone, 2009).

We are able then to define the firm as a complex system, which survives in a competitive environment only trough an efficient combination of resources and energies that are taken from the environment itself, and given back to it with a higher quality (Golinelli, 2002; Miglietta and Peirone, 2009). Firms do more than adjust prices to quantities and vice versa: they are also able, via various learning processes (learning by doing; learning by using; learning by consuming etc.), to interact with the structure of the economic system, so that technologies and tastes at time $\boldsymbol{t}$ are the outcome of the strategic interaction in the market place of agents at time $\boldsymbol{t}_{\mathbf{1}}$. The internal organization of firms is then now influenced by the need to implement the complementarities of the different pieces of knowledge possessed by, and accumulated in, the diverse units (Richardson, 1972).

An organizational policy based on the valorisation of the owners' securities on the market is not suited to the way value is produced in the global capitalism of knowledge, because knowledge is

\footnotetext{
${ }^{7}$ Intrasystemic, concerns relations with the components of the operational structure of the firm; Intersystemic, concerns relations with entities of the systemic context of action.

${ }^{8}$ This process is not happening just at the local level, because new technologies allow to have access to knowledge and relationships that are not circumscribed to a specific location, so increasing the possibility of evolutionary learning.
} 
not a scarce resource. The power remains to the owners, but not always the threat of legal exclusion from a useful resource is effective for the practical purposes of governance. "Property today discovered itself weak and in need of further options and other methods of governance"(p. 132 Rullani, 2009). Capital intensity is no longer a source of protection against competition. Innovations in ICT made communication costs to fall dramatically. Cross-border trade has expanded market size tremendously, and firms that were once oligopolists with the remarkable first mover advantage in their own small domestic markets, now fight it out in a larger, competitive, world market. These environmental trends got trough the firm's paradigm we showed in the first part of this work, changing the nature of delegation in organizations and the ability of top management to exercise control. A recovered competition increases the pace of change, the need for new products and services, and consequently, for initiative and innovation. Employees have to be given more autonomy so that they can respond more quickly to change. Autonomy (and responsibility) may itself be a source of incentive.

This ability to react rapidly to the changes in the economic environment cannot be based only on specialized human capital, but needs complex relationships for realizing and supporting collective actions developed in chains and networks. Only interdependence gives, in fact, the possibility to specialize remaining flexible, and realize great multipliers remaining compliant without a single standard.

\section{In search of a new model}

The new entrepreneurial paradigm based on knowledge, complexity and networks still appears to be vulnerable to criticisms. First, complex systems are fundamentally non-deterministic. However, "self-organization alone cannot explain the adaptation and differential survival of selforganized systems" (Hodgson and Knudsen, 2006) as it tells us nothing about assessment and selection. Here it comes the problem we are going to analyze in this paper: the governance mechanism of this complex system of knowledge interactions.

The model will be then structured around three issues at three levels: selection process by the firm of the subjects to interact with, the governance at the network level, the dynamic path of these relationships in the general economic system. Let's face them in turn.

It is difficult to determine the boundary between a complex system and its environment, because openness (or non-isolation) is an inherent feature of complex systems (Martin and Sunley, 2007). However, boundaries are necessary to understand how the value created should be shared and which are the subjects entitled to be "rewarded". Processes of sharing and networking are rather impermeable to formal economic incentives, because the various parties could hold on to their knowledge, to obtain a bargaining power to spend in the distribution of value chain, making their cognitive difference indispensable into the network relation (hold-up). It is the final result that actually gives value to the network, because the network itself is just a fact. Many analysis about networks seem instead to consider them as interesting objects of analysis "per se", with no tie to any result or indicator of efficiency, making them completely exempt from an assessment.

We look at the nodes of relationships which represent persons as more important than the relationships themselves: in this way the real governance problem in the complex systems of knowledge economy will be to take the different nodes of the network to behave in a manner consistent with the optimization of the total value produced by the available resources 
(Verbeke and Tung, 2012; Capra, 1997). In our description, networks are social infrastructures enabling the complementarity of both nodes and links. This complementarity constitutes the reason for the establishment of networks and is therefore fundamental for their satisfactory functioning as infrastructure. In a network, nodes and links cannot be used at random, but need to be approached in a coordinated way in order to produce a specific service. We sustain the need of an approach based on what Potts (2000) calls an "ontology of connectivity". As showed above, knowledge comes out from interactions, and it is the growth of knowledge that drives the process of economic evolution (Capra, 1997; Metcalfe, 1997; Foster and Metcalfe, 2004).

In our view, the organization is more than just the sum of its parts and, in addition, it becomes intelligent system not only learning through feedback or using the intelligence technique which has access to (technology, software, algorithms, and the encoded information available), but also utilizing the fluid intelligence of people who, at various title, are linked to the enterprise: directly, as owners, managers and employees, or indirectly, as stakeholders with which the firm has established a relationship of mutuality and alignment.

In an economic system that is both partially and generally in a state of connective flux, agents are heterogeneous, capable of learning (Arthur 1993; Potts, 2000) and are using internal models to process environmental signals into expectations. Production systems can be represented in a multi-agent simulation framework as schemata (Holland 1995, Epstein and Axtell 1996), which are sets of strings that operate as a kind of algorithmic suite. Networks are created as agents incorporate the expertise of selected other agents, such that the dynamics of expectations are the dynamics of a complex distributed network process.

\section{The model}

Connections, complementarities and expectations are the three main variables upon which our model is built. Connections are specific direct relationships between elements in the economic system: in the structure of interdependencies and interactions between agents, in technology, organisations and competence. They exist as contracts and in the structure of decision rules and the way that information is processed. Complementarities exist when various activities reinforce each other: performing multiple activities together lowers/(raises) cost, increases economies/(diseconomies) of scope, improves/(depresses) payoffs. Expectations and plans are interrelated constructs (they are both mental models), and each supposes the existence of the other. When the plans of individual agents are stable and widely known (or not), then it follows that expectations will also be stable (or not). When an agent is not able to form suitable expectations of other agents' behaviours, then she will likely restrict her own planning horizon as a means of protection. This will feedback into the system of expectations engendering instability. Here it says the importance of governance. 
Figure 2 Firm as a complex system: a model

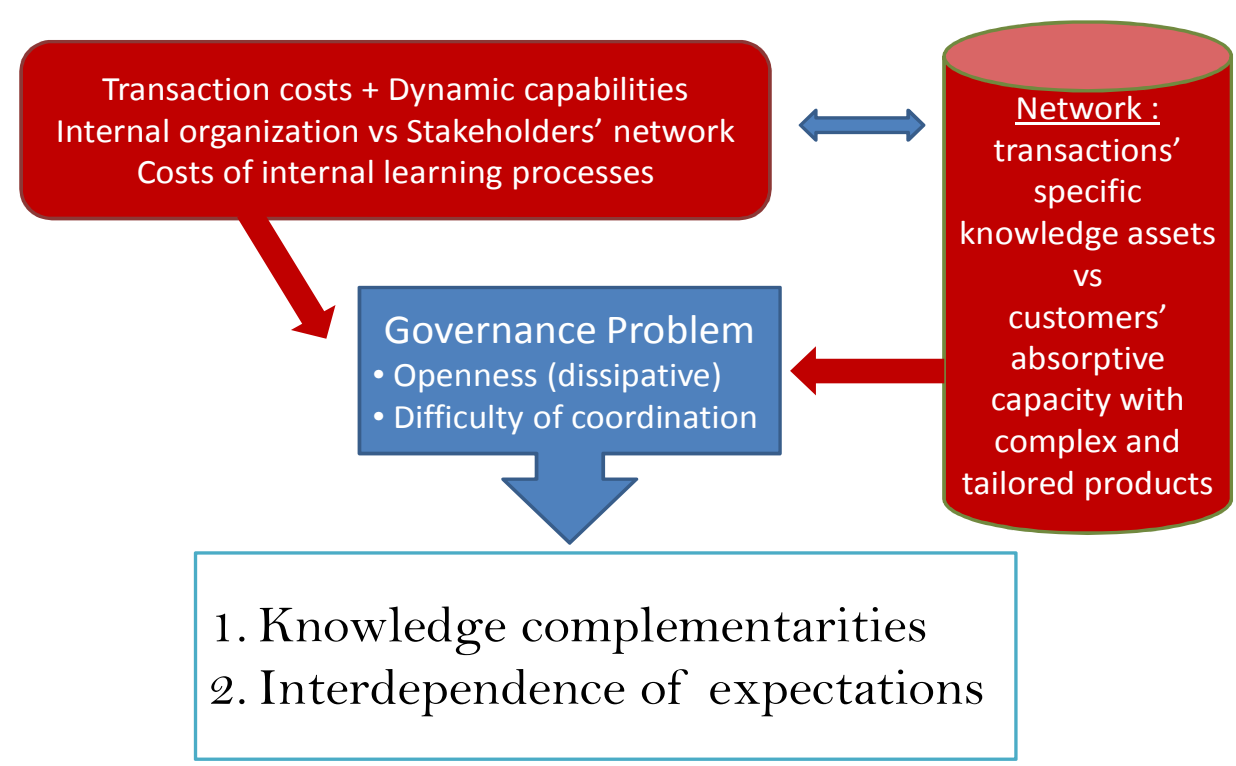

Trust is strongly needed for the stability of these linkages, but it is not the only factor. Aoki (2010) assumes trust as a pre-requisites of the exchange relation, which is represented as a game with expectations based on "reciprocity", so arriving to a Nash equilibrium where agents do not want to change their choice. But from a rational perspective, simply trusting someone probably is not sufficient cause for one to divulge sensitive or private information. In addition, reciprocity does not mean fairness. In a situation of increased uncertainty, agents will tend to increase the interdependence of expectations (Potts, 2000). At the level of firm's relations, network structure will show an increased density of feedback loops, eventually resulting in more chaotic dynamics. A formal way to represent this system is trough models of dynamic graphs that portray the structural-dynamic implications of variation in the density and distribution of connections.

The appropriate framework for this type of analysis is the Random Boolean networks (RBNs) (Kauffman, 1969; Kauffman, 1993). In RBNs the nodes are generated randomly, without any assumption about particular functionality or connectivity. In RBNs the nodes are generated randomly, without any assumption about particular functionality or connectivity. Kauffman proposed the original RBN model, supporting the hypothesis that living organisms could be constructed from random elements, without the need of precisely programmed elements (Kauffman, 1969). Certain types of RBNs are very robust, and have many analogies to living organisms. A RBN consists of $N$ nodes, which can take values of zero or one (Boolean). The state (zero or one) of each node is determined by $K$ connections coming from other (or the same) nodes. 
Random Boolean Network: a set of $n$ elements on a lattice with the state of each element is specified by a Boolean logical operation on a random set of $k$ other elements ( $n k$ family of functions dependent from the macrostates of the system (order, complexity, and chaos)).
- Potential complementarities come from signals from the various actors in the network.

- Agents use internal models to process environmental signals into expectations. The expectation of some variable $\mathrm{X}$, denoted $\mathrm{E}(\mathrm{X})$, is a weighted average of $n$ possible states of $X$ with probabilities $\mathrm{P}_{i}$ used as weights, such that:

$$
\mathrm{E}(\mathrm{X})=\sum_{i=1}^{n} p i X i
$$

- Three operations: agents must construct a list space $(\mathrm{X})$, with an imagination/search operator, of the set of all possibilities; each possibility must be weighted $(\mathrm{P})$ trough a rational/mathematical operator; the array $\mathrm{E}=$ $\mathrm{P}(\mathrm{X})$ must then be interpreted by means of a cognitive/heuristic operator that translates (E) into the space of behaviour (Potts, 2003).

In RBNs, as well as in many dynamical systems, three macrostates can be distinguished: order, complexity, and chaos. Each macrostate is a function of the density of connections in the system (as $k$ varies between 0 and $n$ ). Order is associated with low connectivity, chaos with high connectivity and complexity is a narrow window of intermediate connectivity. If we plot the states of a network in a square lattice where the state of a node depends topologically on its neighbours, and let the dynamics flow, we can easily see which states change, and which ones are stable. In other words, we can observe how much the network changes. Asynchronicity could change drastically the dynamics of a synchronous system, such as the prisoner's dilemma (Huberman and Glance, 1993), and it happens a similar thing for RBNs.

Asynchronous RBNs (ARBNs), where a node is picked up at random, and updated, are fundamentally non-deterministic. Abrupt transitions occur between macrostates so that seemingly minor changes to the number of connections in the system can escalate with dramatic effect as the system percolates from one macrostate into another. This framework shows why the market alone did not work well as a regulator of global interdependencies: the complex system of knowledge economy cannot work only trough self-organisation, by means of random interactions, but the various connection happen because the involved human agents share some common ground (the consonance mentioned above).

This is a useful approach if the specific structure and/or function of a system are very complex and unknown. Creation of value, in this case, can be obtained through a "network of expectations", where the strategic response of a subject will be connected to the same variables used by the other subject to build her expectations. Here, the consistency of an action is "the value for the active agent of the learning that takes place in the reactive agent as a result of the experience of the interaction" (Perez-Lopez, 1993). It may be that, as a consequence of the first interaction, the reactive agent becomes less interested in participating in further interactions, so that, although the first action was effective, there is no guarantee that subsequent actions will be. 
At the general level of the economic system, this process results in a endogenous governance mechanism guided by shared values. For the governance process to be effective it is necessary that the agents' behavior derives from a common ethic and must be leading to focus on substance over form. In corporate governance the linearity and predictability of behaviors allow to guide and control the action in companies thanks to the adoption of some formal models. However, this is not enough, are common and shared values that can guide human action in a harmonious and substantial way, especially during periods of non-equilibrium.

In this model the role of governance is then encouraging behavior based on shared values at a general level.

So, the answer to the question raised by Coase (1937) about the necessity for the economy of the existence of an organization like the firm, is that the firm can be defined primarily a governance mechanisms for knowledge production and exchange. Survival depends on achieving unity, as the efficient complementarity of knowledge and values among the human agents inside the firm and between the various firms in the network. "Achieving optimal economic values is not an economic problem; it cannot be solved by manipulating economic variables alone. It depends on psychological and ethical variables. Only if these latter variables were fixed and could not be altered by learning processes (...) could the optimal economic value be achieved through purely economic processes"' (Perez Lopez, 1987).

\section{The Endogenous Selection Process}

In our model, network structures of interaction will emerge, composed by the signals on her expertise that each agent is transmitting to others. Allowing agents' different internal models, there will be diverse expectations irrespective of whether they have different input data or not (Crilly and Sloan, 2012). When the plans of individual agents are stable and widely known (or not), it follows that expectations will also be stable (or not).

When firms need to maintain control over their strategic assets there will be less interactions in the network. When firms need more independence and allow for knowledge heterogeneity, network interactions will increase.

This model has an influence also on the relationship between markets and institutions (the concept of coherence as explained by Finger et al., 2005). The mainstream economic approach stress that introducing a competitive economic market structure and private sector oriented institutional regimes efficiencies and quality improvements will be obtained. Liberalization is focused on institutional changes, such as unbundling, deregulation, privatization, public-private partnerships, asymmetric regulation, and other practices related to the market structure. This approach neglects the vital feature of networks seen above: the complementarity that defines the interrelations between the various nodes and links.

We sustain that a consonance is needed also with the institutional architectures of the economic environment, assuring a coherence between the technical and the institutional coordination of the four major network functions determines the performance of infrastructures (e.g., interconnection, interoperability, capacity management, and system management), in terms of economic performance, public values and technical system integrity (Finger at al., 2005). The four major network functions are pivotal for enabling the functioning of infrastructures and creating value from the complementarities between the systems' nodes and links. As an example, 
the evolution of financial markets has demonstrated that the institutional characteristics of the market, intended to promote high competition among the players, have almost destroyed an essential infrastructure of the economic system, together with consumer confidence.

Living systems are networks organizationally closed but open to the flows of energy and resources from the environment, and they are sustainable society as far as they are able to satisfy its needs without diminishing the chances of future generations (Capra, 1997). In nature, this happens trough the instinct that command not to dissipate forces and resources. In markets, the search for trust, complementarities and common grounds must become a common and shared responsibility by businesses. This is the way for the company to survival and to grow in modern competition, therefore becoming in some ways "ethical", not for obligation but for its own convenience.

\section{Concluding remarks}

In this paper we draw a model of value creation trough a "network of expectations", allowing for heterogeneous agents with many different business models. The governance mechanism is based on Consonance among agents in the market and a Coherent structure of markets and institutions. This model shows that the impossibility to form suitable expectations of other agents' behaviours takes to a restrictions of planning horizons as a means of protection. This will increase instability trough the interdependence of expectations. The increased density of feedback loops will result in a network structure with more chaotic dynamics. Consonance and coherence allow to exploit complementarities among the different knowledge resources.

In our approach there is no "ethical" or "socially responsible" management rule, nor a definite benchmark, but an endogenous selection process that comes directly from the interaction inside the network, improving the quality and the efficacy of the relationships. It comes out that the core objective of management strategy is the creation of value, not the appropriation of value (Goshal and Moran, 2005).

We also tried to understand how this value can be shared between firm and stakeholders avoiding resources' dissipation. The model shows that achieving profits does not guarantee the organization's survival or continuity. Survival is given by the ability to find new ways to collect and utilize information about stakeholders' utility function, improving at the same time the capability (by means of feedback) of selecting which transaction partners are more and less likely to act opportunistically in the future. Our model portrays a deliberate resources selection, accumulation, and recombination trough a network of expectations based on coherence, targeted to optimize the total value produced by the available resources, regulated by dynamic feedbacks. The selection is linked to:

1. the productive and organisational architecture,

2. the phase of development,

3. the need for the firm to control strategic resources or allowing knowledge heterogeneity. This governance mechanism of the network gives to firms a crucial source of value in the global economy, that is the ability of their entire productive systems to react rapidly to external dynamics. 


\section{References}

Aghion, P., \& Howitt, P. (1998). Endogenous growth theory, Cambridge, MIT Press. Antonelli, C. (2008), Localised technological change, London, Routledge.

Aoki, M. (2010) "Individual Social Capital, Social Networks, and Their Linkages to Economic Game", paper presented at the Annual World Bank Conference on Development Economics 2010.

Arrow, K.J. (1974), The limits of organization, New York, W.W. Norton.

Arthur, W.B. (1983), "Competing technologies and lock-in by historical events: the dynamics of allocation under increasing returns". IIASA Working Paper, WP-83-90-, Laxemburg: Austria.

Coase, R. H. (1937). “The nature of the firm”. Economica 4, 386-405.

Crilly D., Sloan P. (2012), "Enterprise logic: explaining corporate attention to stakeholders from the "inside-out", Strategic Management Journal 33: 1174-1193, John Wiley \&Sons.

David, P. A. (1985). "Clio and the Economics of QWERTY". American Economic Review. 75, 332-37.

Finger, M., Groenewegen, J., Künneke, R. (2005), “The quest for coherence between institutions and technologies in infrastructures", Journal of Network Industries , 6 (4): 227-60.

Foss, N.J. (ed.). (1998) Resources, Firms and Strategies, Oxford University Press: Oxford.

Freeman E.R. (1984) Strategic Management a Stakeholder Approach, Pitman, Marshfild.

Golinelli G.M. (2008) L' approccio sistemico al governo dell'impresa, Verso la scientificazione dell'azione di governo. CEDAM, Padova.

Goshal S. and Moran P. (2005) "Towards a good theory of management", in Piramal G. and Birkinshaw J. (eds), Sumantra Ghoshal on Management: A Force for Good, pp. 1-30, Prentice Hall.

Goshal S., Nahapiet J. (1998) "Social capital, intellectual capital, and the organizational advantage", Academy of Management Review, Vol. 23. No. 2, 242-266.

Harris, M., \& Raviv, A. (1991). "The Theory of Capital Structure". Journal of Finance. 46, 297355.

Harrison J., Bosse D. and Phillips R. (2010), "Managing for stakeholders, stakeholder utility functions, and competitive advantage”, Strategic Management Journal, 31: 58-74 (2010), John Wiley \&Sons.

Marshal A., Principles of economics, Macmillan, London, 1965.

Maturana, H., \& Varela, F. (1992), The Tree of Knowledge. Shambala.

Miglietta A., Peirone D. (2009), "Finance, Innovation and the Value of the Firm", IJBE International Journal of Business and Economics, Vol.8 (1), pp. 31-46, ABER (USA)

Morroni, M. (2011) "New insights on the interaction between transaction costs and capabilities considerations in shaping organisational boundaries", Discussion Paper n.113, Dipartimento di Scienze Economiche - Università di Pisa.

Peirone, D. (2007). "Knowledge and venture funding: complementarities and financial contracts". Industrial and Corporate Change 16, pp. 851-873, Oxford University Press.

Penrose, E. (1959). The theory of the growth of the firm, Oxford, Basil Blackwell.

Perez Lopez, J. A. (1977) "Moral, ética y negozio", Technical note, IESE, FHN-113, January.

Perez Lopez, J. A. (1993) "Summary of Concepts for Ethical Analysis".

Rajan R. and Zingales L. (2001), "The influence of the Financial Revolution on the nature of the firm”, American Economic Review, 2, 206-211. 
Richardson, G. (1972). “The Organization of Industry”. Economic Journal, 82, 883-896.

Romer, P.M. (1986). "Increasing returns and long run growth". Journal of Political Economy. 94, 1002-10037.

Romer, P.M. (1990). "Endogenous technological change". Journal of Political Economy. 98, 71103.

Rosenberg, N. (1976). Perspectives on technology, Cambridge, Cambridge University Press.

Teece, D.J. (1998). "Capturing value from knowledge assets: The new economy, markets for know-how and intangible assets". California Management Review 40, 55-79.

Verbeke A. and Tung V. (2012), "The Future of Stakeholder Management Theory: A Temporal Perspective", Journal of Business Ethics, March 2012, Springer.

Vicari S., \& Cillo, P. (2006). Developing a Brokering Capacity within the Firm: The Enactment of Market Knowledge.

Williamson, O. E. (1985). The economic institutions of capitalism: Firms, markets, relational contracting. New York, Free Press.

Zingales, L. (2000). "In search of new foundations”. Journal of Finance. 4, 1623-1653. 